\title{
A CROSS-SECTIONAL AND COMPARATIVE STUDY OF STIGMA IN UNDERGRADUATE MEDICAL STUDENTS TOWARDS MENTALLY ILL PATIENTS
}

\author{
Srinivasa Rao Sireesha ${ }^{1}$, Usha Venkata Ramana Lanka², J. Mayurnath Reddy³, Chennamsetty Siva Kumar ${ }^{4}$ \\ ${ }_{1}^{1}$ Associate Professor, Department of Psychiatry, Institute of Mental Health, Osmania Medical College, Hyderabad. \\ ${ }^{2}$ Associate Professor, Department of Psychiatry, Institute of Mental Health, Osmania Medical College, Hyderabad. \\ ${ }^{3}$ Professor, Department of Psychiatry, Institute of Mental Health, Osmania Medical College, Hyderabad. \\ ${ }^{4}$ Assistant Professor, Department of Psychiatry, Institute of Mental Health, Osmania Medical College, Hyderabad.
}

ABSTRACT: BACKGROUND: Stigma and negative discriminatory attitudes towards psychiatric patients are common in general public. These attitudes are also demonstrated by medical students. This can have a detrimental effect on care of mentally ill patients. This study was aimed to find out to what extent these negative attitudes can be improved by psychiatry postings.

METHODS: Sixty $1^{\text {st }}$ year medical students and sixty internee students of an urban medical college were assessed for stigma towards mentally ill patients using a semi-structured intake proforma, dangerousness scale (DS) and social distance scale (SDS). Data was analysed using SPSS.

RESULTS AND OBSERVATION: The mean score of first year medical students on SDS was $11.27 \pm 3.45$ standard deviation (sd) and that of internees $10.25 \pm 3.5 \mathrm{sd}$. The mean score of DS was $32.73 \pm 8.2 \mathrm{sd}$ for first years and $28.2 \pm 5.8$ sd for internees. Overall, SDS scores was not significant between the groups with item 2 and 3 of SDS scale alone being significant. The total DS scores was significant between the two groups being reflected in items 1, 2, 3 and 5 of DS scale. There was a significantly positive correlation between total SDS scores and DS scores. Prior contact with mental illness did not make any difference in the stigma perceived in the first year group. There was no association between stigma and sociodemographic factors. The two weeks psychiatry posting brought about a partial change in attitude of students.

CONCLUSIONS: The need to increase psychiatry posting both qualitatively and quantitatively was perceived by us and other earlier researchers too. Stricter psychiatry posting guidelines need to be followed for an effective change in the medical students, who will be the key health care giver in future.

KEYWORDS: Medical Students; Mental Illness; Stigma; Attitudes.

HOW TO CITE THIS ARTICLE: Srinivasa Rao Sireesha, Usha Venkata Ramana Lanka, J Mayurnath Reddy, Chennamsetty Siva Kumar. "A Cross-Sectional and Comparative Study of Stigma in Undergraduate Medical Students Towards Mentally Ill Patients." Journal of Evolution of Medical and Dental Sciences 2015; Vol. 4, Issue 94, November 23; Page: 15963-15969,

DOI: $10.14260 /$ jemds/2015/2326.

INTRODUCTION: People with mental illness frequently face stigma, prejudice and discrimination throughout the world from both public and health care providers. ${ }^{1}$ According to WHO, it was estimated that there are 450 million people in the world currently suffering from some kind of mental illness constituting $14 \%$ of the global burden of the disease. ${ }^{2}$ Stigma can be defined as combination of problems of knowledge (Ignorance); attitudes (Prejudice) and behaviour (Discrimination). ${ }^{3}$ It can be damaging particularly when it comes from medical professionals.

The dimensions of stigma are: (1) Perceived stigma which refers to one's belief that others perceive an individual as socially unacceptable; (2) Self-stigma which refers to similar internalised perception of oneself leading to fear of seeking help or disclosing one's illness due to stigma associated with illness; (3) Social distance refers to one's desire to maintain distance from people with a particular illness; (3) Social distance refers to one's desire to maintain

Financial or Other, Competing Interest: None

Submission 02-11-2015, Peer Review 03-11-2015,

Acceptance 13-11-2015, Published 21-11-2015.

Corresponding Author:

Dr. Usha Venkata Ramana Lanka,

8-3-169/A/45/D-1; Surya Residency,

Siddhartha Nagar, Vengalraonagar,

Hyderabad-500038, Telangana.

E-mail: dasikausha@gmail.com

DOI:10.14260/jemds/2015/2326. distance from people with a particular illness; and (4) Dangerousness refers to one's belief that the patient is dangerous. ${ }^{4}$

There is widespread stigma about mental illness and psychiatric services in India. Films, newspaper reports, and magazines often depict mental illness as chronic, incurable, and as a subject matter of ridicule. Mental hospitals formed the mainstay of treatment until few years ago and this has led to strong negative attitudes among the lay public, increasing the stigma. ${ }^{5}$ The shifting of the place of care to the general hospital setting has contributed significantly to the process of destigmatization of psychiatric illnesses and psychiatric care. ${ }^{6}$

Stigma affects patient's interactions, social network, employment opportunities and quality of life in general. It also effects patients self-esteem, and leads to disruption of family. 7,8 Stigma and stereotyped negative attitudes towards psychiatric patients contribute to deficient health care provided to these patients. Medical students also express such stigma towards psychiatric patients. ${ }^{9}$ In an earlier study, $89 \%$ of preclinical medical students opposed psychiatric patients marrying into their families and $89 \%$ opposed mental patients teaching their children. ${ }^{10}$ Another study concluded that medical students attitudes to psychiatry patients were based on opinions formed during childhood, at school and clinical postings. ${ }^{11}$ 
One study however found that medical students experience in general was associated with more positive attitudes towards mental illness. ${ }^{12}$ Psychiatric problems are common among patients seen in general practice (About $25 \%$ ) and specialty clinics (About $15 \%$ ). ${ }^{13}$ So knowledge and positive attitude towards mental health is necessary for all health care professionals and not psychiatrists alone.

A study from India found that Undergraduate (UG) medical students have multiple lacunae in knowledge towards psychiatric disorders and treatment. ${ }^{14}$

A proper training in psychiatry during UG course makes the student a better doctor. Undergraduate medical students are trained in psychiatry during final year MBBS and internship as part of their training as per Medical Council of India (MCI) guidelines in India. Students may bring with them preconceived negative attitudes about these psychiatric patients.

It is therefore important to understand these negative attitudes to enable them to deal positively and effectively towards these patients in their practice. A few Indian studies have assessed the impact of psychiatric posting in changing the attitudes of medical students towards mental illness. ${ }^{15,16,17}$ This study was carried out to assess to what extent stigma has been modified by exposure to UG psychiatry training.

\section{AIMS:}

1. To study the stigma of first year medical students towards mentally ill patients.

2. To study the stigma of internee medical students towards mentally ill patients.

3. To compare the stigma between the two study groups.

METHODS: Appropriate permission was obtained from the concerned authorities of an urban medical college before carrying out this study.

Study Universe: Medical students from $1^{\text {st }}$ year and internees.

Study Design: Cross sectional.

Sampling Design: Simple random sampling.

Data Collection: Sixty students each of first year and internees of an urban medical college were included in the study in September 2015 by simple random sampling. Students received an explanatory statement outlining the purpose of the study beforehand and were informed that participation was voluntary.

Confidentiality issues were explained and taken care of. The inclusion criterion for first group was first year students, who have not attended psychiatry training yet. An inclusion criterion for 2nd group was internees who had undergone theory and clinical postings in psychiatry.

Theory classes included 20 didactic lectures on important psychiatry topics. Clinical postings included bedside teaching, case presentation, lectures and seminars for two weeks. Each student filled up a self-reported intake proforma including sociodemographic data, details about prior contact with mentally ill persons and knowledge about mental illness.
They then rated the items on Social Distance Scale (SDS). ${ }^{18}$ and Dangerousness Scale (DS). ${ }^{19}$ Consent was implied by completion of the questionnaire.

Social Distance Scale: Comprises of 7 statements that refer to interaction with the target individuals. Each statement was rated by the subjects on a 4 -point Likert scale $(0=$ definitely willing to, $3=$ definitely unwilling). A composite measure of social distance is derived by totalling the scores of all statement. The higher the score, more the discrimination and stigmatization is demonstrated. The internal consistency (Cronbachs alpha) of this measure was 0.75.17

Dangerousness Scale: By Penn and Link was used to gauge individual beliefs about whether a person who is or has been mentally ill is likely to be a danger to others. It has 8 items. Responses to each item was rated on a 7-point Likert scale from strongly disagree $=1$ to strongly agree $=7$ with the midpoint being no opinion. A high statement response indicated a more negative attitude. It has internal consistency of 0.78 .18

Statistical Methods: Descriptive statistics like means, percentages and standard deviation were used to summarise sociodemographic data, SDS and DS scores. Inferential statistics like t-test, Chi square, Anova and Pearsons correlation test were used to compare the differences between stigma scores across the two groups. The level of significance was set at $\mathrm{p} \leq 0.05$. Data was analysed using SPSS version 20.

RESULTS: A total of 60 undergraduate medical students and 60 internees participated in the study. There was a slight female preponderance in first year group (53.33\%), males were higher in internee group (55\%). All first year students $(100 \%)$ and majority of internees were below 25 yrs. (65\%). Majority of parents were literates in both groups (95\% vs 98\%).

Majority of mothers were housewives ( $66.8 \%$ vs $74.7 \%$ ) and fathers were professionals $(71.76 \%$ vs $54.78 \%)$. Most study subjects of both groups were from urban background $(76.76 \%$ vs $71.78 \%)$. Both study groups were matched for gender, religion, domicile, parental education and occupation. A small minority of parents were doctors (20\% vs $13.28 \%$ ). (Table No. 1)

The mean scores on Social Distance Scale (SDS) of first year medical students was found to be $11.27 \pm 3.45 \mathrm{sd}$ and that of internee students were $10.25 \pm 3.5 \mathrm{sd}$. The mean scores of dangerousness scale (DS) was found to be $32.73 \pm 3.47$ sd for first year medicos and $28.20 \pm 5.8$ sd for internees.

The association between overall SDS score of first year and internee students was not significant on t-test ( $p$ value $=0.112$ ) suggesting that attending psychiatry posting did not improve stigma. The association between overall DS scores of both study groups were found to be statistically significant. (P value=0.001) (Table No. 2). There was however a positive correlation between the total scores of SDS and DS. Correlation being significant at 0.01 level. (Table No. 3) 
SDS scores of individual items across both study groups were analysed using t-test. There was a statistically significant difference between scores of first year and internee groups for items 2 and 3 of SDS scale. ( $P$ value $=0.006,0.027)$. This suggests that attending psychiatric postings has brought down stigma of medical students towards psychiatric patients partially and hence was reflected in these two items only. (Table No. 4)

Similarly, DS scores of individual items across both study groups were analysed using t-test. There was a statistically significant association between both groups of medical students for item number 1, 2, 3, 5 of DS. ( $P$ value $=0.018,0.000,0.036,0.018)$. This indicates that perception of dangerousness of psychiatric patients has come down by attending psychiatric posting considerably. (Table No. 5)

No significant association was found in SDS and DS total scores when first year group with and without prior contact with psychiatric patients (Friend/family/unspecified contact) were compared. (P value=0.658). (Table No. 6)

There was no significant association between gender and total score of both scales. This suggests that both males and females did not differ from each other in stigma $(P$ value $=0.991,0.688)$. (Table No. 7 )

Similarly religion of study subjects of both groups was not associated significantly with total scores of both SDS and DS. (P value $=0.401,0.835$ ) This suggests that religion did not play any role in influencing stigma of the study subjects. (Table No. 8)

DISCUSSION: Our study showed modest improvement in stigma of medical students after attending psychiatry postings. This is in line with an earlier study where final year medical students had more favourable attitude towards mentally ill when compared to first year students. ${ }^{17,20}$ Internees showed significant improvement after attending psychiatry postings on item 2 - "Mentally ill patient as a coworker" and item 3 "Having a person with mental illness as neighbour" of SDS scale in our study. But items like "Renting a room to a mentally ill person;" "Allowing your children to marry someone with mental illness;" "Allowing mentally ill persons as caretaker of children;" "Introducing a mentally ill person to a young woman;" and "Recommending a mentally ill person for a job" did not improve.

This suggests that stigma has come down partially, but not completely. Probably mental illness was still perceived as inheritable with patients being unpredictable and impulsive with disruptive behaviour. On dangerousness scale items 1, 2, 3 , and 5 showed significant difference across the two groups. DS item 1 - "If a group of former mental patients live nearby, I would not allow my children to go alone;" item 2 "Recommend mental patient as a teacher in a school;" item 3 "Mental patients are unpredictable" and item 5 - "The main purpose of mental hospitals should be to protect public from mentally ill" showed significant difference across the two groups.

This suggests internees who have finished two weeks of psychiatry posting have developed understanding that mentally ill patients are less dangerous and mental hospitals are meant for treatment of psychiatric patients for successful integration back into society and not for detention or custodial care alone. Items like "They cannot trust mental patients;" "Not allow children to play in the vicinity of mental patient's homes;" "Cannot forget the fact that mental patients are dangerous" and "Whether to grant license for fire arms to mentally ill patients;" showed no improvement in scores. This suggests that mentally ill patients were still perceived as dangerous by medical students in certain aspects. Stigma, negative attitudes and discrimination towards mentally ill was observed in earlier studies. ${ }^{21,22,23,24,25}$

Earlier research indicated that females have positive attitudes and less stigma towards persons with mental illness. ${ }^{21,26}$ In another recent study it was found that female participants were less stereotyped and more benevolent (Kind) than males and those from urban background had more positive attitudes than rural in separatism and restrictiveness. ${ }^{27}$ One study reported that Chinese and South Korean medical students had higher stigma scores than their British counterparts. ${ }^{21}$

Our study did not find any association between stigma and sociodemographic factors like gender and religion suggesting that maybe they did not have a major influence in forming attitudes.

Amongst the first year medical students, regardless of prior contact with psychiatric patients there was no difference in sigma scores. This is in line with an earlier study where there was no significant difference in attitudes towards mentally ill regardless of contact., ${ }^{20}$ but contrary to other studies where scores improved in those who were familiar with mental illness. ${ }^{21,27}$ This suggests that contact itself was not sufficient to bring about a change in stigma. Other culture related factors also need to be studied for their influence. Education plays a very important role in reducing stigma and improving attitude towards mentally ill. ${ }^{28}$

Research from India has demonstrated positive effects of undergraduate psychiatric posting. ${ }^{17,27}$ Another study suggested adequate modifications to existing medical curriculum would help to improve attitude of medical students towards mentally ill. ${ }^{15}$ A few studies from India and abroad indicated that 4-8 weeks of posting in psychiatry resulted in significant improvement of stigma and attitude scores of medical students than 2 weeks alone. ${ }^{26,29,30}$

But in contrary other studies from India concluded that exposure to psychiatry as per current curriculum seems to have limited influence on bringing a positive influence.16,31 Studies from Middle East also failed to find a favourable impact of medical education on stigmatised attitude of medical students. ${ }^{32}$

Indian Psychiatric Society (IPS) in 2010 submitted a document to the MCI, prepared by its Psychiatric Education Committee stating that a medical student on graduation should be able to deliver mental health services at primary care level including amongst other things, identifying signs and symptoms of common psychiatric illnesses and able to develop helpful and humane attitude toward psychological, psychiatric, and behavioural difficulties. ${ }^{33}$

The nature of mental illness is such that it causes personal havoc and chaotic disturbances within the family and society; so in spite of being exposed to such patients at professional level and seeing them improve; the personal bias 
towards such patients continues. In all honesty nobody will be willing to perceive them as less dangerous, specially when they are in acute violent state. It is advised to all caregivers to take measures to protect themselves and the patient keeping in view the unpredictability of their behaviour during acute states.

CONCLUSIONS: Psychiatric postings at undergraduate level is essential to bring about a positive attitude towards psychiatric patients amongst doctors irrespective of their future chosen speciality. Present training in India is not fully successful in ameliorating the stigma perceived. More extensive training as suggested by Psychiatric education committee of IPS to MCI will bring about an effective change in the undergraduates. ${ }^{33}$ In addition increasing general awareness about psychiatric conditions and their treatability amongst the public will also help in reducing stigma and promoting positive attitudes.

\section{LIMITATIONS:}

1. Size of sample is very small and from only one urban medical college and not representative of all students and hence generalisation of results needs to be done with caution. Larger study sample including students from other medical colleges is recommended for better understanding of factors affecting stigma.

2. A longitudinal study would be better to assess the impact of psychiatry posting in changing the attitude of the same study subject over a period of time. Ours was not a longitudinal study.

Future Recommendations: As proposed earlier. ${ }^{5}$ the interest, awareness and attendance can be improved only by making psychiatry as independent exam and making compulsory long case presentation of psychiatry case in final year MBBS practical exam. There is an urgent need to review and increase number of theory classes, practicals and bedside training. Compulsory assessment exam is being recommended at the end of psychiatry posting. This will go a long way in preparing medical students to diagnose and treat psychiatry patients effectively and empathetically without any bias.

\section{REFERENCES:}

1. Thompson AH, Stuart H, Bland RC et al. Attitudes about schizophrenia from the pilot site of WPA worldwide campaign against the stigma of schizophrenia. Soc Psychiatry Epidemiol 2002;37:475-82.

2. WHO Mental Health Gap Action Program (MHGAP).2008. Last accessed on 2015 Sept 26th. Available from http://www.who int/mental_health/mhgap/en/.

3. Thorncroft G, Rose D, Kasam A, Sartorius N. Stigma: Ignorance, prejudice or discrimination? $\mathrm{Br} J$ psychiatry.2007;190;192-3.

4. Corrigan P, Markowitz FE, Watson A, Rowan D et al. An attribution model of public discrimination towards persons with mental illness. J Health Soc Behav. 2003,44:162-79.
5. Roy Abraham Kallivayalil. The importance of psychiatry in undergraduate medical education in India. Indian J Psychiatry. 2012 Jul-Sep; 54(3): 208-216.

6. Agarwaal SP, Goel DS, Ichhpujani RL, Salhan RN, Shrivatsava S. Mental health - An Indian perspective (1946-2003) New Delhi: Directorate General of Health Services, Ministry of Health and Family Welfare; 2004.

7. Tuckett D. An introduction to medical sociology. Bristol Tavistock pub.1976;344-52.

8. Van Pen Tillaart S, Kurtz D, Cash P. Powerlessness, marginalised identity and silencing of health care concerns: Voiced realities of woman living with a mental health diagnosis. Int J Ment Health. 2009;18:153-63.

9. Wigney T, Parker G. Medical student observations on a career in psychiatry. Aust NZ J Psychiatry 2007;41:72631.

10. Hutchinson G. Perceptions about mental illness among preclinical medical students in Trinidad and Tobago. West Indian Medical Journal.1999;48(2):81-84.

11. Hill D. Acceptance of psychiatry by the medical students. British Medical Journal.1960;1:917-18.

12. Roth D. Attitudes towards mental illness in medical students: Does personal and professional experience with mental illness make a difference? Medical Education. 2000;34(3);234-6.

13. Sood M, Sharan S. A pragmatic approach to integrating mental health in understanding training: The AIIMS experience and work in progress. Natl Med J India.2011;24:108-10. [PubMed].

14. Chawla JM, Balhara YP, Sagar R et al. Undergraduate medical students attitude towards psychiatry: A crosssectional study. Indian J Psychiatry. 2012;54:37-40.

15. Yadav T, Arya K, Kataria $O$ and Balhara YP. Impact of psychiatry education and training on attitude of medical students towards mentally ill: A comparative analysis. Indian J Psychiatry. 2012;21:22-31.

16. Gulati $\mathrm{P}, \mathrm{Das} \mathrm{S}$, Chavan BS. Impact of psychiatry training on medical students towards mental illness and psychiatry. Indian J Psychiatry.2014;56:271-7.

17. Konwar R, Pandil PK, Prakash J and Rythem. Does psychiatry rotation in undergraduate curriculum bring about a change in the attitude of medical students towards concepts and practice of psychiatry: A comparative analysis. Ind J Psychiatry. 2012;21:144-7.

18. Penn DL, Guynan K, Daily T et al. Dispelling the stigma of schizophrenia. What sort of information is best? Schiz Bulletin.1994;20(3):567-78.

19. Link BG, Cullen FT. Contact with mentally ill and perception of how dangerous they are? Journal of health and social behaviour.1986;27:289-303.

20. Mas A, Hatim A. Stigma in mental illness: Attitudes of medical students towards mental illness. Med J Malaysia. 2002;57(4):433-9.

21. Korszun A, Dinos S, Ahmed K, Bhui K. Medical student attitudes about mental illness: Does medical education reduce stigma. Acad Psychiatry 2012;36(3):197-214.

22. Farooq Naeem, Ayub M, Javed Z, Irfan M. Stigma and psychiatric illness. A survey of medical students and doctors in Lahore, Pakisthan. J Ayub Med coll. Abbotabad 2006;18(3):46-9. 
23. Rudnick A. Attitudes of pre-clinical medical students towards psychiatric patients before and after an early clinical experience. Canadian Medical Education Journal.2011;2(1):e11-4.

24. Boyle M J, Williams B, Brown T, Molley A. Attitudes of undergraduate health science students towards patients with intellectual disability, substance abuse and acute medical illness; a cross-sectional study. BMC Medical education.2010;10:71.

25. Murthy RS, Khandelwal S. Undergraduate training in psychiatry. World perspective. Indian J Psychiatry 2007;49:169-74.

26. Reddy J P,Tan SM,Azmi MT et al. The effect of a clinical posting in psychiatry on attitudes of medical students towards psychiatry and mental illness in Malaysian medical school. Ann Acad Med Singapore. 2005;34:50510.

27. Poreddi V, Thimmaiah R and Math SB. Attitude towards people with mental illness among medical students. Journal of Neurosciences in rural practice.2015;6(3):349-54.
28. Roberts LM, Wiskin C, Roalfe A et al. Effects of exposure to mental illness in role play on UG students attitudes. Fam Med.2008;40:477-83.

29. Rajgopal M and Kuruvilla K. Medical students attitudes to psychiatry: The effect of a 4-week posting. Indian J of social psychiatry.2007;3,3:238-59.

30. Adebowale TO, Adelufosi AO, Ogunwala A et al. The impact of a psychiatry clinical rotation on the attitude of Nigerian medical students to psychiatry. Afr J Psychiatry.2012;15:185-8

31. Lingeswaran A. Psychiatric curriculum and its impact on attitude of Indian UG medical students and interns. Indian J Psychol Med. 2010;32:119-27.

32. AY P, Save D, Fidanoglu O. Does stigma concerning mental disorders differ through medical education: A survey among medical students in Istanbul. Soc psychiatry Epidemiol.2006;41:63-7.

33. Indian Psychiatric Society: Recommendations for Undergraduate (MBBS) syllabus in Psychiatry. Report prepared by the Psychiatric Education Committee of Indian Psychiatric Society chaired by RC Jiloha. 2010.

\begin{tabular}{|c|c|c|c|c|c|}
\hline \multicolumn{2}{|c|}{ Parameter } & $\begin{array}{c}\text { Ist Year } \\
\mathrm{N}=60\end{array}$ & $\begin{array}{c}\text { Intern } \\
\mathrm{N}=60\end{array}$ & Chi-sq & Significance \\
\hline \multirow{2}{*}{ Age } & $<25$ years & $60(60.6 \%)$ & $39(39.4 \%)$ & $25.455^{\mathrm{a}}$ & $0.000^{*}$ \\
\hline & $>25 y e a r s$ & 0 & $21(100 \%)$ & & \\
\hline \multirow{2}{*}{ Gender } & Male & $28(45.9 \%)$ & $33(54.1 \%)$ & $.834^{a}$ & 0.361 \\
\hline & Female & $32(54.2 \%)$ & $27(45.8 \%)$ & & \\
\hline \multirow{2}{*}{ Background } & Rural & $14(45.2 \%)$ & $17(54.8 \%)$ & $.391^{\mathrm{a}}$ & 0.532 \\
\hline & Urban & $46(51.7 \%)$ & $43(48.3 \%)$ & & \\
\hline \multirow{3}{*}{ Religion } & Hindu & $53(51 \%)$ & $51(49 \%)$ & $.329^{a}$ & .848 \\
\hline & Muslim & $5(45.5 \%)$ & $6(54.5 \%)$ & & \\
\hline & Christian & $2(40 \%)$ & $3(60 \%)$ & & \\
\hline \multirow{2}{*}{ Mother's Education } & Literate & $57(51.4 \%)$ & $54(48.6 \%)$ & $1.081^{a}$ & 0.298 \\
\hline & Illiterate & $3(33.3 \%)$ & $6(66.7 \%)$ & & \\
\hline \multirow{2}{*}{ Father's Education } & Literate & $58(49.6 \%)$ & $59(50.4 \%)$ & $.342^{\mathrm{a}}$ & 0.559 \\
\hline & Illiterate & $2(66.7 \%)$ & $1(33.3 \%)$ & & \\
\hline \multirow{4}{*}{ Mother's Occupation } & Homemaker & $42(48.3 \%)$ & $45(51.7 \%)$ & $2.394^{\mathrm{a}}$ & 0.495 \\
\hline & Professionals & $17(54.8 \%)$ & $14(45.2 \%)$ & & \\
\hline & Semi-skilled & $1(100 \%)$ & 0 & & \\
\hline & Unskilled & $0(0 \%)$ & $1(100 \%)$ & & \\
\hline \multirow{4}{*}{ Father's Occupation } & Unemployed & $2(100 \%)$ & 0 & $6.782^{\mathrm{a}}$ & 0.079 \\
\hline & Professional & $43(56.6 \%)$ & $33(43.4 \%)$ & & \\
\hline & Semiskilled & $11(36.7 \%)$ & $19(63.3 \%)$ & & \\
\hline & unskilled & $4(33.3 \%)$ & $8(66.7 \%)$ & & \\
\hline \multirow{2}{*}{ Parent doctor } & Yes & $12(60 \%)$ & $8(40 \%)$ & $.960^{\mathrm{a}}$ & .327 \\
\hline & No & $48(48 \%)$ & $52(52 \%)$ & & \\
\hline & parison & odemogra & if fortom & 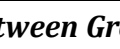 & \\
\hline
\end{tabular}

\begin{tabular}{|c|c|c|c|c|c|c|}
\hline Group & $\begin{array}{c}\text { SDS } \\
\text { Mean (SD) }\end{array}$ & $\begin{array}{c}\text { SDS } \\
\text { T-value }\end{array}$ & $\begin{array}{c}\text { SDS } \\
\text { Sig (2 tailed) }\end{array}$ & $\begin{array}{c}\text { DS } \\
\text { Mean (SD) }\end{array}$ & $\begin{array}{c}\text { DS } \\
\text { T-value }\end{array}$ & $\begin{array}{c}\text { DS } \\
\text { Sig (2 tailed) }\end{array}$ \\
\cline { 1 - 2 } $\begin{array}{c}\text { Ist Year } \\
\text { n=60 }\end{array}$ & $11.27(3.45)$ & & & $32.73(8.2)$ & & \\
\cline { 1 - 1 } $\begin{array}{c}\text { Interns } \\
\text { n=60 }\end{array}$ & $10.25(3.5)$ & 1.6 & 0.112 & $28.20(5.8)$ & 3.474 & $0.001^{* *}$ \\
\hline \multicolumn{7}{|c|}{ Table 2: Comparison Between Groups with SDS and DS $^{+}$Total Scores } \\
\hline
\end{tabular}

*SDS-Social distance scale

tDS-Dangerousness scale

**. Correlation is significant at the 0.01 level (2-tailed). 


\begin{tabular}{|c|c|c|c|}
\hline Scores & Statistics & SDS Total & DS Total \\
\hline \multirow{4}{*}{ SDS Scores } & $\begin{array}{c}\text { Pearsons } \\
\text { Correlation }\end{array}$ & 1 & $0.421^{* *}$ \\
\cline { 2 - 4 } & Sig.(2-tailed) & \multicolumn{2}{|c|}{$0.000^{* *}$} \\
\cline { 2 - 4 } & $\mathrm{N}$ & $0.421^{* *}$ & 1 \\
\hline \multirow{3}{*}{ DS Scores } & $\begin{array}{c}\text { Pearsons } \\
\text { Correlation }\end{array}$ & \multicolumn{2}{|c|}{0.000} \\
\cline { 2 - 4 } & \multicolumn{2}{|c|}{ Sig.(2-tailed) } & \multicolumn{2}{|c|}{120} \\
\hline \multicolumn{2}{|c|}{ Table 3: Correlations Between SDS Total Scores and DS Total Scores } \\
\hline
\end{tabular}

**. Correlation is significant at the 0.01 level (2-tailed).

\begin{tabular}{|c|c|c|c|c|}
\hline Item & Group & Mean(SD) & T-value & Significance \\
\hline \multirow{2}{*}{1} & $1^{\text {st }}$ Year $(n=60)$ & $1.67(0.70)$ & \multirow{2}{*}{1.096} & \multirow{2}{*}{0.275} \\
\hline & Internees $(\mathrm{n}=60)$ & $1.52(0.79)$ & & \\
\hline \multirow{2}{*}{2} & $1^{\text {st }}$ Year $(\mathrm{n}=60)$ & $1.62(0.88)$ & \multirow{2}{*}{2.794} & \multirow{2}{*}{$0.006^{* *}$} \\
\hline & Internees(n=60) & $1.18(0.81)$ & & \\
\hline \multirow{2}{*}{3} & $1^{\text {st }}$ Year $(\mathrm{n}=60)$ & $1.35(0.84)$ & \multirow{2}{*}{2.237} & \multirow{2}{*}{$0.027^{* *}$} \\
\hline & Internees $(n=60)$ & $1.02(0.79)$ & & \\
\hline \multirow{2}{*}{4} & $1^{\text {st }}$ Year $(n=60)$ & $1.93(1.05)$ & \multirow{2}{*}{0.253} & \multirow{2}{*}{0.800} \\
\hline & Internees $(\mathrm{n}=60)$ & $1.88(1.10)$ & & \\
\hline \multirow{2}{*}{5} & $1^{\text {st }} \operatorname{Year}(\mathrm{n}=60)$ & $2.18(0.87)$ & \multirow{2}{*}{-1.537} & \multirow{2}{*}{0.127} \\
\hline & Internees $(\mathrm{n}=60)$ & $2.42(0.78)$ & & \\
\hline \multirow{2}{*}{6} & $1^{\text {st }} \operatorname{Year}(\mathrm{n}=60)$ & $1.27(0.91)$ & \multirow{2}{*}{1.174} & \multirow{2}{*}{0.243} \\
\hline & Internees $(n=60)$ & $1.08(0.78)$ & & \\
\hline \multirow{2}{*}{7} & $1^{\text {st }} \operatorname{Year}(\mathrm{n}=60)$ & $1.25(0.83)$ & \multirow{2}{*}{0.661} & \multirow{2}{*}{0.510} \\
\hline & Internees $(n=60)$ & $1.15(0.82)$ & & \\
\hline
\end{tabular}

* SDS-Social distance scale

\begin{tabular}{|c|c|c|c|c|}
\hline Item & Group & Mean(SD) & T-value & Significance \\
\hline \multirow[t]{2}{*}{1} & $1^{\text {st }}$ Year $(n=60)$ & $4.48(1.9)$ & \multirow{2}{*}{2.39} & \multirow[t]{2}{*}{$0.018^{* *}$} \\
\hline & Internees $(n=60)$ & $3.68(1.76)$ & & \\
\hline \multirow[t]{2}{*}{2} & $1^{\text {st }} \operatorname{Year}(\mathrm{n}=60)$ & $3.65(1.88)$ & \multirow{2}{*}{4.340} & \multirow{2}{*}{$.000^{* *}$} \\
\hline & Internees $(\mathrm{n}=60)$ & $2.37(1.3)$ & & \\
\hline \multirow{2}{*}{3} & $1^{\text {st }}$ Year $(n=60)$ & $4.77(1.78)$ & \multirow{2}{*}{2.126} & \multirow{2}{*}{$.036^{* *}$} \\
\hline & Internees $(\mathrm{n}=60)$ & $4.10(1.6)$ & & \\
\hline \multirow[t]{2}{*}{4} & $1^{\text {st }} \operatorname{Year}(\mathrm{n}=60)$ & $4.12(1.8)$ & \multirow{2}{*}{.993} & \multirow{2}{*}{.323} \\
\hline & Internees $(\mathrm{n}=60)$ & $3.82(1.46)$ & & \\
\hline \multirow{2}{*}{5} & $1^{\text {st }}$ Year $(n=60)$ & $3.58(2.09)$ & \multirow{2}{*}{2.405} & \multirow{2}{*}{$.018^{* *}$} \\
\hline & Internees $(n=60)$ & $2.73(1.76)$ & & \\
\hline \multirow{2}{*}{6} & $1^{\text {st }} \operatorname{Year}(n=60)$ & $3.47(2.02)$ & \multirow{2}{*}{1.207} & \multirow{2}{*}{.230} \\
\hline & Internees $(\mathrm{n}=60)$ & $3.07(1.58)$ & & \\
\hline \multirow[t]{2}{*}{7} & $1^{\text {st }}$ Year $(\mathrm{n}=60)$ & $4.32(1.63)$ & \multirow{2}{*}{.365} & \multirow{2}{*}{.715} \\
\hline & Internees $(\mathrm{n}=60)$ & $4.22(1.35)$ & & \\
\hline \multirow[t]{2}{*}{8} & $1^{\text {st }}$ Year $(\mathrm{n}=60)$ & $4.32(1.8)$ & \multirow{2}{*}{.602} & \multirow{2}{*}{.549} \\
\hline & Internees $(n=60)$ & $4.12(1.84)$ & & \\
\hline
\end{tabular}

* DS-Dangerousness scale

\begin{tabular}{|c|c|c|c|c|}
\hline Item & Group & Mean(SD) & t value & Significance \\
\hline SDS(total score) & With Contact $(n=30)$ & $11.06(3.17)$ & \multirow[t]{2}{*}{-.446} & \multirow[t]{2}{*}{.658} \\
\hline SDS (total score) & Without contact $(n=30)$ & $11.46(3.75)$ & & \\
\hline DS (total score) & With Contact(n=30 & $32.53(8.91)$ & \multirow{2}{*}{-.186} & \multirow{2}{*}{.853} \\
\hline DS (total score) & Without contact $(n=30)$ & $32.93(7.7)$ & & \\
\hline & $\begin{array}{r}\text { e 6: Comparison Betwe } \\
\text { Prior Contact w }\end{array}$ & $\begin{array}{l}1^{\text {st }} \text { Year Stu } \\
\text { Total Score }\end{array}$ & $\begin{array}{l}\text { With, } \\
\text { est] }\end{array}$ & \\
\hline
\end{tabular}




\begin{tabular}{|c|c|c|c|c|}
\hline Item & Gender & Mean (SD) & t-value & Significance \\
\hline DS-Total & Male(61) & $30.46(7.10)$ & -.011 & .991 \\
\hline & Female(59) & $30.47(7.89)$ & & .688 \\
\hline SDS-Total & Male(61) & $10.89(3.02)$ & .402 & \\
\hline \multicolumn{5}{c}{ Table 7: Comparison Between Gender with DS Total } \\
\hline & Scores and SDS Total Scores (t-test) \\
\hline
\end{tabular}

\begin{tabular}{|c|c|c|c|c|}
\hline Score & Religion & Mean(SD) & F value & Significance \\
\hline DS Total & Hindu(n=104) & $30.13(7.3)$ & .922 & .401 \\
\hline & Muslim(n=11) & $33.27(8.38)$ & & \\
\hline & Christian(n=5) & $31.40(9.34)$ & & .835 \\
\hline SDS Total & Hindu(n=104) & $10.70(3.58)$ & .180 & \\
\hline & Muslim (n=11) & $11.36(3.139)$ & & \\
\hline & Christian(n=5) & $10.60(2.793)$ & Table 8: Comparison Between Religion and DS \\
\hline \multicolumn{7}{|c|}{ Total Scores and SDS Total Scores (Anova) } \\
\hline
\end{tabular}

